\title{
PENGEMBANGAN APLIKASI KOPDAR (FORUM KOPI DARAT) DENGAN MENGGUNAKAN FRAMEWORK CODEIGNITER
}

\author{
Anang Syaifur Rochman \\ Fakultas Teknik, Program Studi Teknik Informatika \\ Universitas Muria Kudus \\ Email: 201751011@std.umk.ac.id \\ Tutik Khotimah \\ Fakultas Teknik, Program Studi Teknik Informatika \\ Universitas Muria Kudus \\ Email: tutik.khotimah@umk.ac.id
}

\begin{abstract}
ABSTRAK
CV. Filomena IT Media merupakan perusahaan yang bertujuan untuk menciptakan karya IT berupa produk, software, video tutorial, e-book project dan website yang berguna untuk semua orang dalam mengembangkan usaha. Kopdar (Kopi Darat Indonesia) merupakan sebuah situs web yang menyediakan berbagai layanan yang disediakan oleh CV. Filomena IT Media. Pada versi sebelumnya baik tampilan maupun versi software yang digunakan menggunakan versi yang lama. Hal ini menyebabkan adanya beberapa fitur yang tersedia tidak bisa digunakan sebagaimana mestinya. Oleh karena itu, untuk mengikuti perkembangan software perlu dilakukan upgrade pada code yang dipakai agar fitur yang tersedia tetap berjalan normal. Fitur yang ada dalam sistem tersebut antara lain Screencast, Artikel, Forum Diskusi, dan Manajemen System pengembangan perangkat lunak, metodologi yang digunakan adalah Software Re-engineering. Tahap pertama yang dilakukan adalah Reverse Engineering. Tahap kedua adalah analisa fitur untuk memberikan gambaran tentang fungsionalitas dari website ini. Tahap ketiga perancangan database. Tahap keempat proses coding. Tahap kelima proses testing. Tahap keenam proses production, Tahap terakhir adalah proses maintenance. Dengan mengubah struktur kode menggunakan framework codeigniter terbaru, fitur yang ada dapat berjalan dengan normal.
\end{abstract}

Kata kunci: landing page, kopdar, tutorial, codeigniter, model view controller

\section{ABSTRACT}

CV. Filomena IT Media is a company designed to create IT works consisting of products, software, video tutorials, e-book projects and websites that are useful for everyone in developing a business. Kopdar (Kopi Darat Indonesia) is a website that provides various services provided by CV. Filomena IT Media. In the previous version both the version and the software version used were using the old version. This results in some features that cannot be used as they should. Therefore, to keep abreast of the software needs to be updated on the code used so that the available features continue to run normally. Existing features in this system include Screencast, Articles, Discussion Forums, and Management Systems for software development, the development method used is Software Re-engineering. The first stage is Reverse Engineering. The second stage is feature analysis to provide an overview of the functionality of this website. The third stage is database design. The fourth stage is coding. The fifth stage is testing. The sixth stage is production process, the last stage is the maintenance process. By changing the structure of the code using the latest version codeigniter framework, that feature can run normally.

Keywords: landing page, kopdar, tutorial, codeigniter, model view controller 


\section{PENDAHULUAN}

Semakin berkembangnya Teknologi Informasi dan Komunikasi di dunia membuat para pegiat IT diharuskan untuk mengikuti perkembangan teknologi agar bisa terus bertahan didunia industri. Tidak terkecuali di Indonesia, dari 176 negara, posisi Indonesia mengalami peningkatan dari rangking 114 pada tahun 2015 menjadi 111 pada tahun 2016. Indonesia termasuk dalam 10 besar most dynamic country untuk kenaikan nilai IP-TIK dari 3,85 pada tahun 2015 menjadi 4,33 pada tahun 2016 (Internatonal Telecommunicaton Union, dalam Measuring Informaton Society Report 2017). Untuk itu, para pegiat IT di Indonesia mulai untuk terus berkembang agar bisa bertahan dan bersaing dengan SDM IT dari luar negeri. Salah satu cara yang bisa dilakukan adalah mencari tutorial dan memantau perkembangan Teknologi dibidang software. Namun, orang awam yang baru terjun dalam dunia IT tentu akan kesulitan untuk memahami semua materi yang ada dari internet.

Ada banyak sekali situs yang telah menyediakan materi-materi untuk mengembangkan software dalam Bahasa Indonesia. Salah satunya adalah Kopdar. Dalam penelitian kali ini penulis mengembangkan dengan menggunakan framework codeigniter.

Beberapa penelitian pernah dilakukan dan dijadikan sebagai bahan referensi dalam penelitian ini sebagai adalah Perancangan Sistem Informasi Pernikahan Dan Status Pernikahan Kantor Uurusan Agama Kecamatan Canduang Agam Berbasis Web Dengan Framework Codeigniter[1], Aplikasi Pendaftaran Seminar Menggunakan Metode MVC Berbasis Website Menggunakan Framework Codeigniter 3.1.10 [2], Aplikasi Video Pembelajaran dengan Konsep Youtube [3], Rancang Bangun Sistem Administrasi Kerja Praktek dan Tugas Akhir Berbasi Web dengan menggunakan framework codeigniter[4], dan Teknologi Pemrograman Framework Model View Controller pada Sistem Infromasi Penasehat Akademis (studi kasus STMIK Amik Riau)[5].

Berdasarkan penelitian penelitian tersebut yang menerapkan codeigniter dalam berbagai kasus permasalahan, penulis mencoba mengembangkan aplikasi kopdar dengan menggunakan framework codeigniter terbaru, saat penelitian ini dilaksanakan versi yang terbaru adalah versi 3.1.10. Tujuan dari penelitian ini adalah agar fungsi yang masih berjalan pada website bisa mengikuti perkembangan terbaru saat ini.

Permasalahan yang mendasari penelitian ini adalah saat menggunakan versi coding lama suatu hari nanti maka kode tersebut akan terjadi error/tidak bisa digunakan lagi, oleh karena itu diganti struktur kode yang ada dengan menggunakan framework terbaru untuk mengikuti perkembangan dari bahasa pemrograman itu sendiri.

\section{METODOLOGI PENELITIAN}

Secara umum metode yang digunakan dalam penelitian ini meliputi:

a. Analisa kebutuhan

Pada tahap ini ada beberapa tahap yang dilakukan. Pertama menganalisis kebutuhan software yang akan digunakan untuk mengembangkan aplikasi ini. Seperti pemilihan software text editor dan tools untuk manajemen database. Yang kedua adalah menganalisis kebutuhan hardware yang akan digunakan.

b. Perancangan Database

Sebelumnya, telah ada database yang dibuat dan digunakan pada aplikasi kopdar versi lama. Oleh karena itu pada tahap perancangan database, dilakukan revisi terhadap database lama menyesuaikan fitur - fitur yang akan dikembangkan.

c. Proses Implementasi.

Proses implementasi menggunakan bahasa pemrograman PHP yang dikemas dalam framework codeigniter dan dikombinasi dengan javascript agar hasil bisa menjadi lebi interaktif. Sedangkan database yang digunakan adalah MySQL.

d. Proses Testing

Setelah proses implementasi selesai, selanjutnya adalah proses testing dimana aplikasi kopdar diisi dengan dummy data untuk memastikan proses yang dibuat berjalan sebagaimana mestinya. 
e. Proses Production

Yang dilakukan dalam tahap ini adalah proses upload aplikasi yang telah matang pada server hosting.

\section{TINJAUAN PUSTAKA}

\subsection{Codeigniter}

Codeigniter adalah sebuah framework php yang bersifat open source menggunakan metode MVC (Model, View, Controller) untuk memudahkan developer atau programmer dalam membangun sebuah aplikasi berbasis web tanpa harus membuatnya dari awal[6]

\subsection{MVC (Model View Controller)}

MVC merupakan suatu konsep yang memisahkan pengembangan aplikasi berdasarkan komponen utama yang membangun sebuah aplikasi seperti manipulasi data, user interface, dan bagian yang menjadi kontrol aplikasi[7]. MVC digunakan untuk memisahkan akses data dan logika bisnis dari presentasi data dan interaksi pengguna. Pemisahan dilakukan agar setiap perubahan dalam logika presentasi atau logika bisnis tidak berpengaruh satu sama lain sangat kompleks. Solusi pemisahan MVC diharapkan dapat meningkatkan fleksibilitas dan usabilitas aplikasi. Arsitektur MVC memisahkan aplikasi menjadi tiga bagian, yaitu Model, View dan Controller. Model: Representasi database, termasuk tabel desain terhadap hubungan yang ada antar tabel. Fungsi utama dari model ini adalah untuk menangani data, mengambil data dari database, memasukkan data ke dalam database, manipulasi data melalui validasi data. View: View untuk membuat model data yang diberikan dan akan mengirimkan gerak/aktivitas dari konsistensi tampilan data ke perubahan yang terjadi. Dengan mengelompokkan semua tampilan dan kode presentasi di satu tempat, akan memudahkan untuk mengubah tampilan tanpa mempengaruhi logika bisnis dan data. Controller: Controller mendefinisikan perilaku yang terjadi pada aplikasi, dan kemudian memetakannya ke dalam tindakan dari pengguna ke model. Pengontrol akan sangat erat kaitannya dengan View, karena setiap interaksi pengguna yang akan dilakukan akan ditunjukkan oleh View dan direspon oleh Controller. Di dalam controller akan ada metode yang akan merespon perilaku aplikasi [6].

\subsection{Use Case Diagram}

Use case diagram atau diagram use case merupakan pemodelan untuk menggambarkan kelakuan (behavior) sistem yang akan dibuat. Diagram use case mendiskripsikan sebuah interaksi antara satu atau lebih aktor dengan sistem yang akan dibuat[8].

\subsection{Activity Diagram}

Activity Diagram menggambarkan workflow (aliran kerja) atau aktivitas dari sebuah sistem atau proses bisnis [9].

\subsection{Deployment Diagram}

Deployment Diagram digunakan untuk menggambarkan detail bagaimana komponen disusun di infrastruktur system [9].

\section{HASIL DAN PEMBAHASAN}

4.1 Gambaran Sistem Kopdar dengan Menggunakan Framework Codeigniter dan Konsep MVC 
Penelitian pada sistem aplikasi kopdar ini tidak menggunakan bahasa pemrograman php secara natif namun sudah menerapkan prinsip Object Oriented Programming yang telah dikemas dalam framework codeigniter.

Struktur kerja Codeigniter dimulai dari browser yang akan berinteraksi melalui controller. Kemudian controller akan menerima dan membalas semua permintaan dari browser. Untuk data, controller akan meminta model dan untuk pengontrol UI/template akan meminta untuk melihat. Bila browser meminta halaman web maka router akan menemukan controller yang seharusnya menangani permintaan tersebut. Nantinya akan digunakan controller untuk mengakses data dan tampilan model untuk menampilkan data. Penggambaran sistem dibuat dengan menggunakan deployment diagram. Gambar 1 berikut adalah deployment diagram dari aplikasi kopdar.

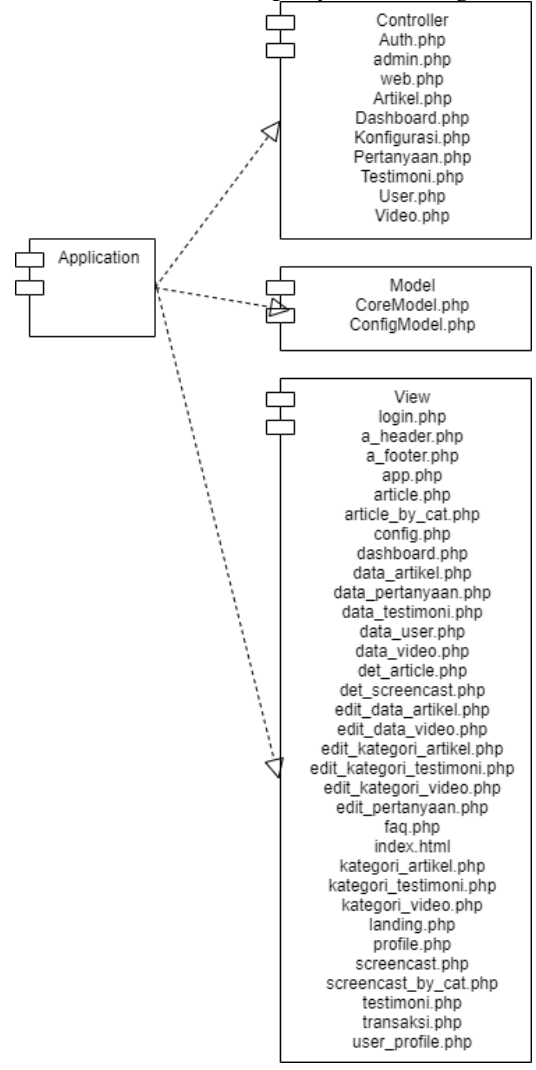

Gambar 1. Deployment Diagram

\subsection{Perancangan Use Case Diagram}

Pada perancangan kopdar aktor dibagi menjadi 2 yaitu admin dan user. Masing-masing aktor memiliki hak akses yang berbeda. Use case diagram dapat dilihat pada gambar 2 berikut. 


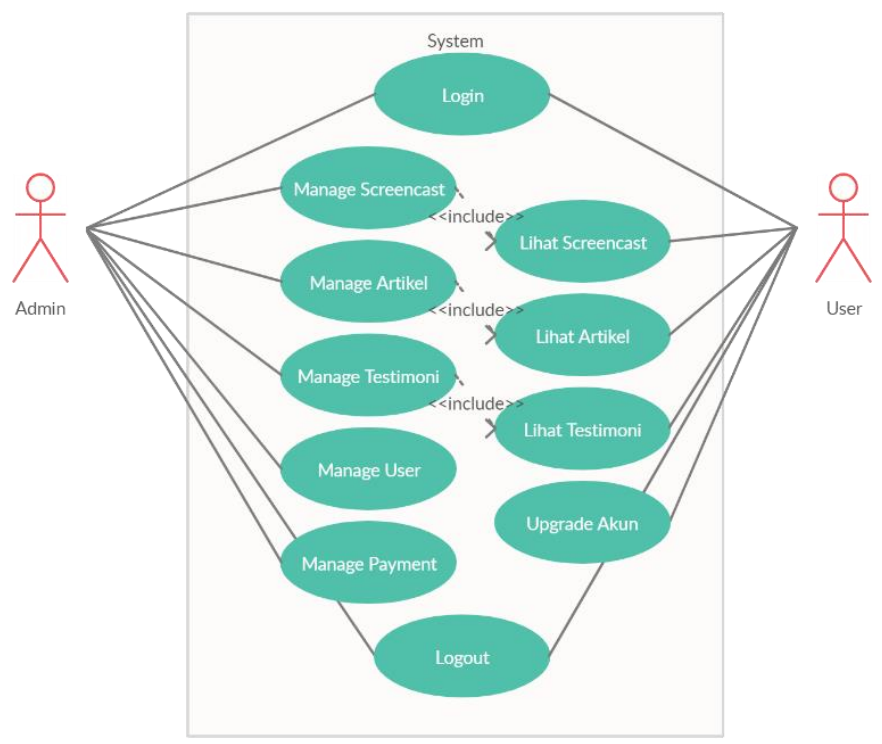

Gambar 2. Use Case Diagram

\subsection{Perancangan Activity Diagram}

Berikut pada gambar 3 adalah activity diagram yang menggambarkan proses pembuatan status user. 


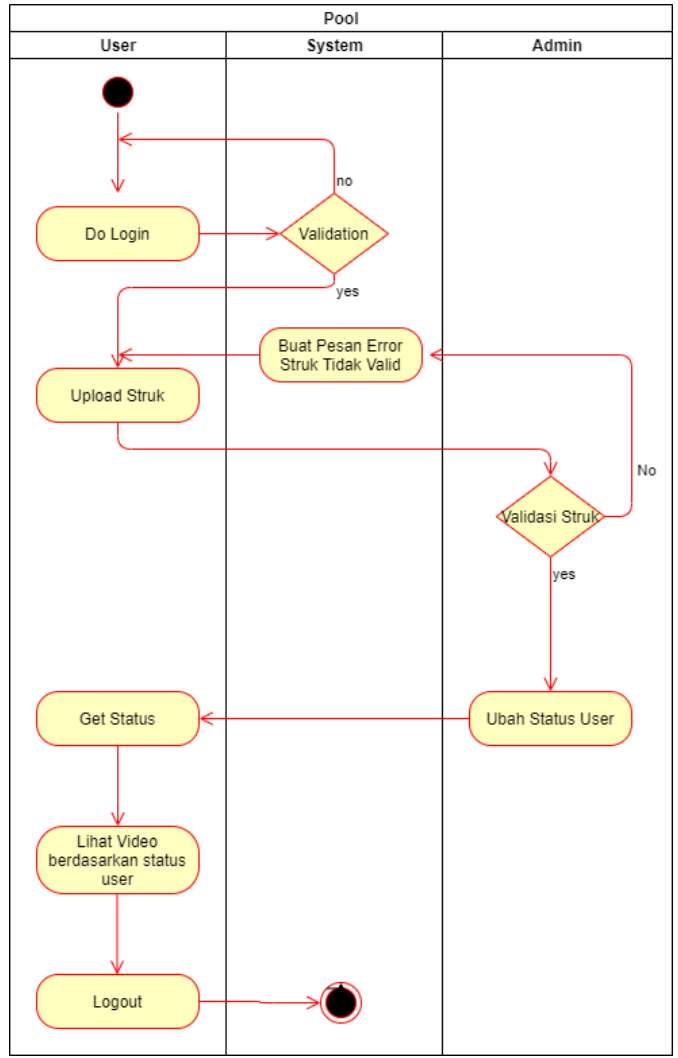

Gambar 3. Activity Diagram

\subsection{Relasi Tabel}

Adapun tabel dan relasi yang dihasilkan dapat dilihat pada gambar 4 berikut.

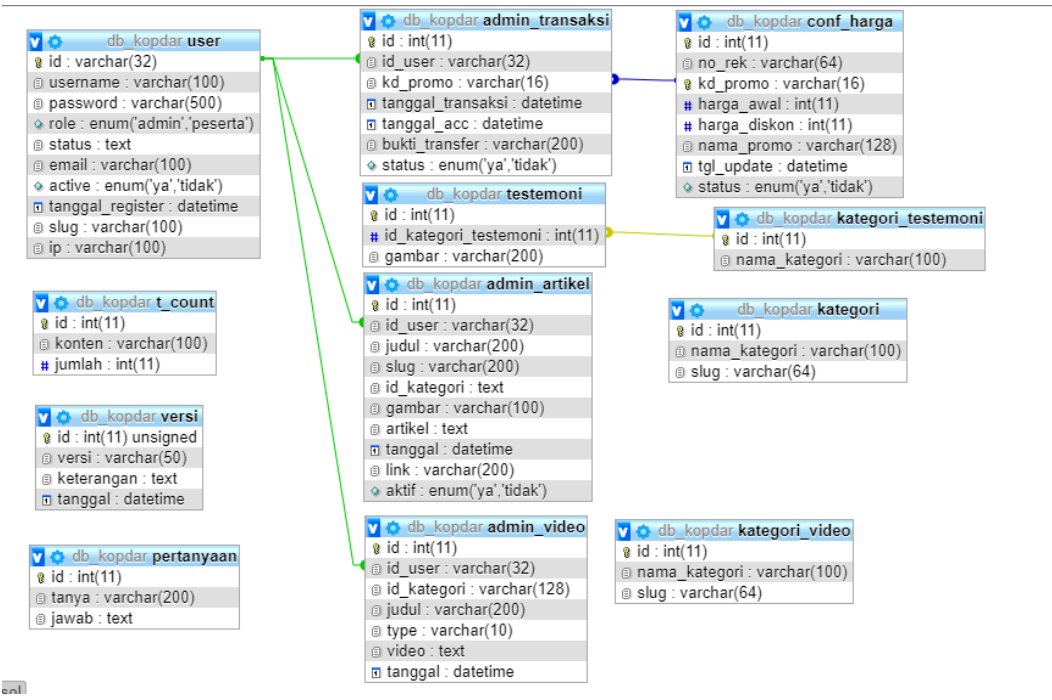

Gambar 4. Relasi Antar Tabel 


\subsection{Implementasi Sistem}

Pada sistem aplikasi kopdar terdapat dua role utama yaitu admin dan user. Role user sendiri dibagi menjadi 2 yaitu user free dan user premium. Penerapan social media authentification hanya berlaku untuk role user, sedangkan untuk role admin tetap login melalui form login biasa dengan username dan password.

\section{a. Role User}

\section{Landing Page}

Halaman yang menjadi tampilan awal saat membuka alamat website aplikasi Kopdar. Untuk tampilan halaman ini dapat dilihat pada gambar 5.
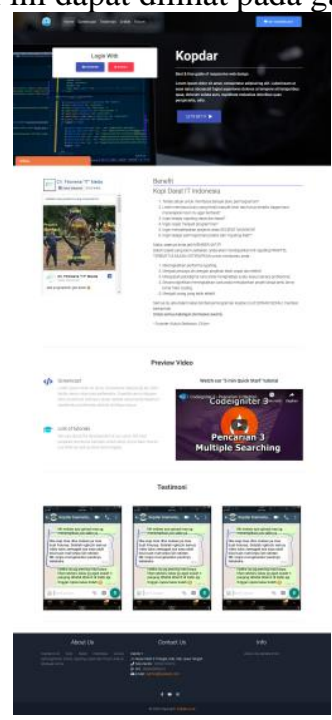

Gambar 5. Halaman Landing Page

Pada halaman inilah implementasi dari social media authentification dengan mengklik tombol facebook/google maka halaman website akan langsung dialihkan ke laman social media yang sedang dipakai oleh user. Pada gambar 6 dibawah menampilkan form login dari google. Sedangkan pada gambar 7 menampilkan form login dari facebook.

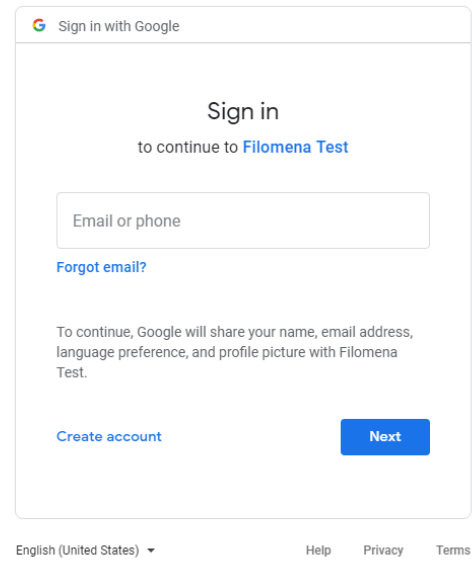

Gambar 6. Google Form 


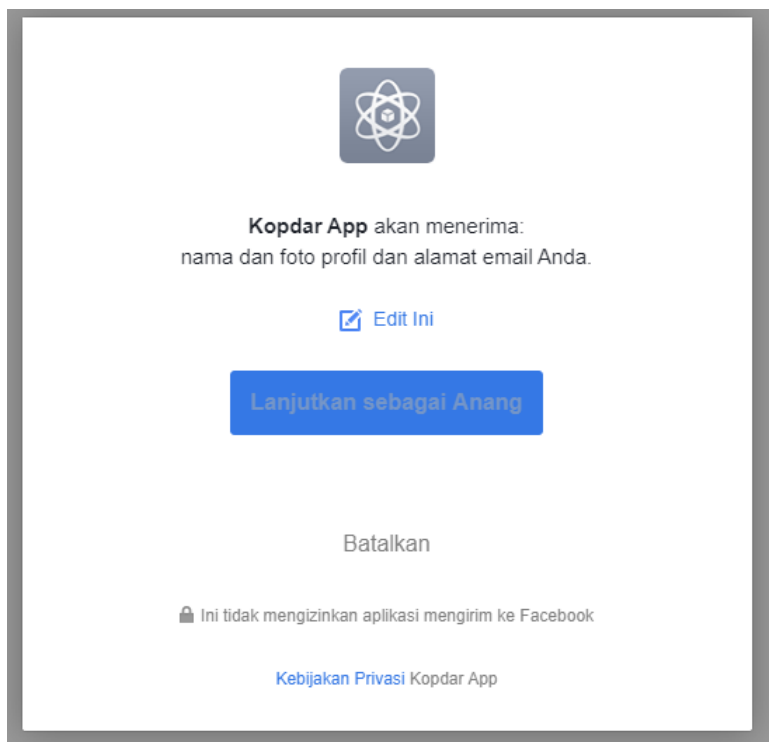

Gambar 7. Facebook Login

2. Screencast Page

Halaman ini bertujuan untuk menampilkan screencast yang telah dibuat oleh admin, baik itu free ataupun premium. Untuk tampilan halaman ini dapat dilihat pada gambar 8 .

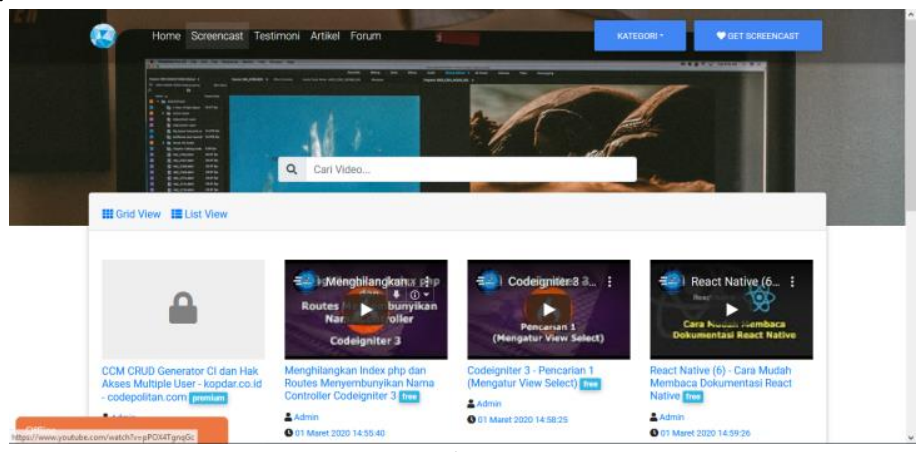

Gambar 8. Halaman Screencast 
Potongan kode tampilan screencast

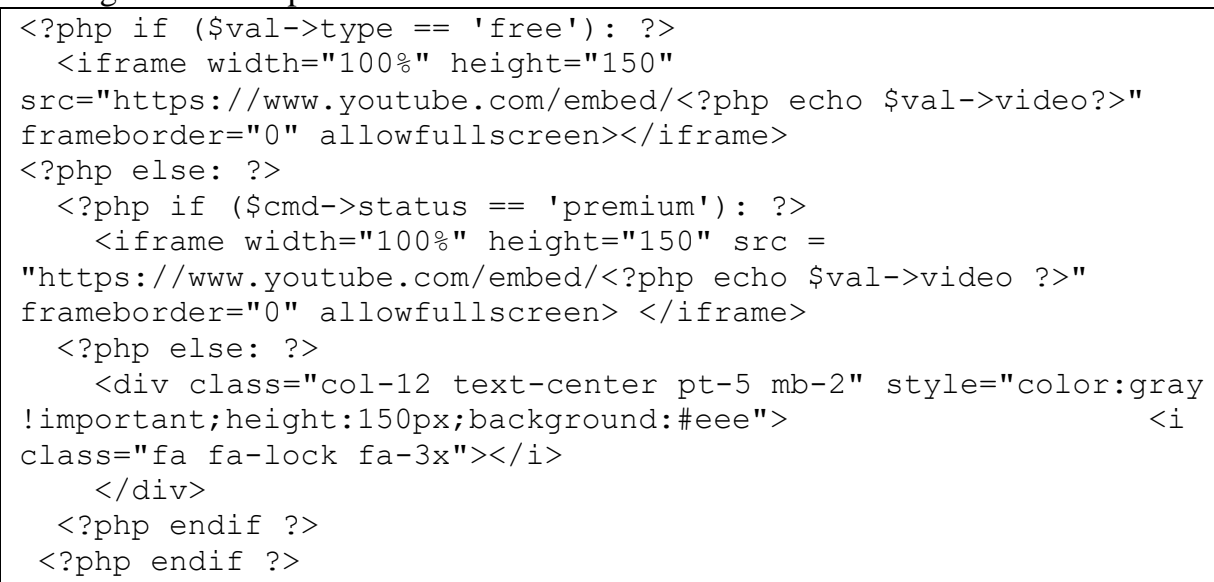

Kode diatas merupakan potongan kode untuk filter tampilan screencast bahwa bila user tersebut berstatus free maka thumbnail yang ditampilkan untuk video premium akan berupa icon lock, namun bila status user tersebut premium maka akan menampilkan iframe yang berisi video premium.

3. Article Page

Halaman ini berisi semua artikel yang telah diinputkan oleh admin. Untuk tampilan halaman ini dapat dilihat pada gambar 9 .

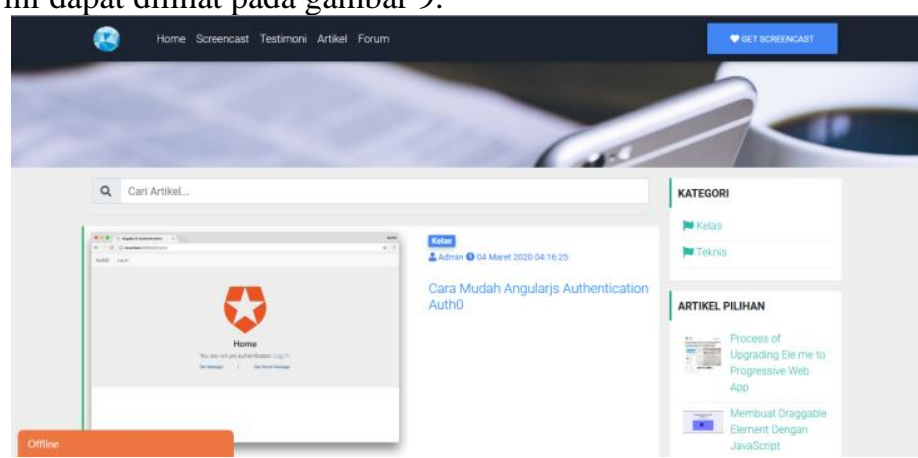

Gambar 9. Halaman Article 
4. Testimoni Page

Halaman ini berisi semua testimoni yang telah diinputkan oleh admin. Untuk tampilan halaman ini dapat dilihat pada gambar 10.

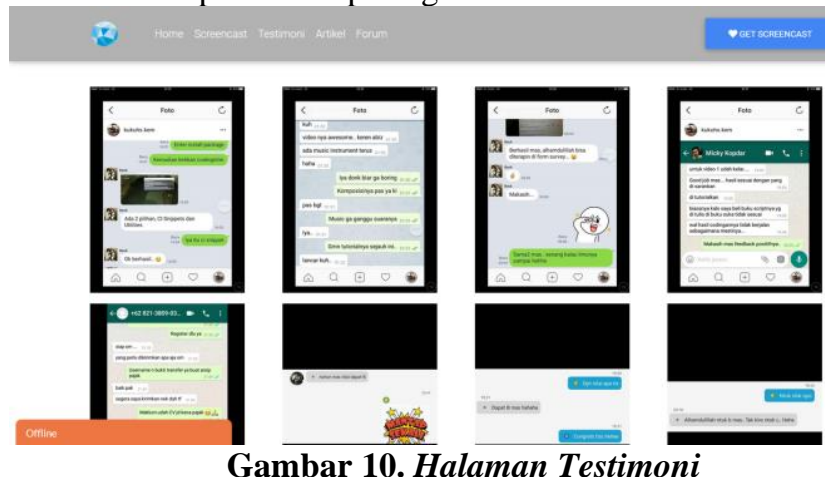

b. Role Admin

1. Login

Halaman ini bertujuan untuk admin agar bisa masuk ke dalam sistem untuk mengolah data. Untuk tampilan halaman ini dapat dilihat pada gambar 11.

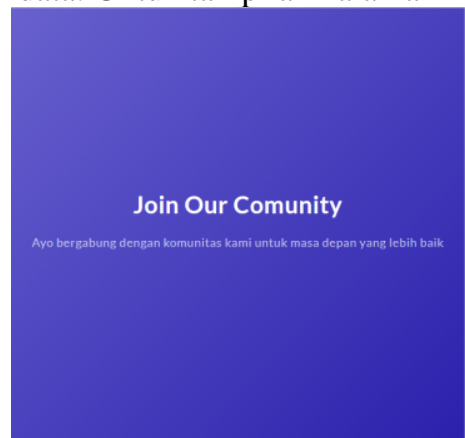

Sign In To Admin

Gambar 11. Halaman Login Admin

2. Dashboard

Halaman ini berisi informasi tentang jumlah user, artikel, dan screencast. Untuk tampilan halaman ini dapat dilihat pada gambar 12.

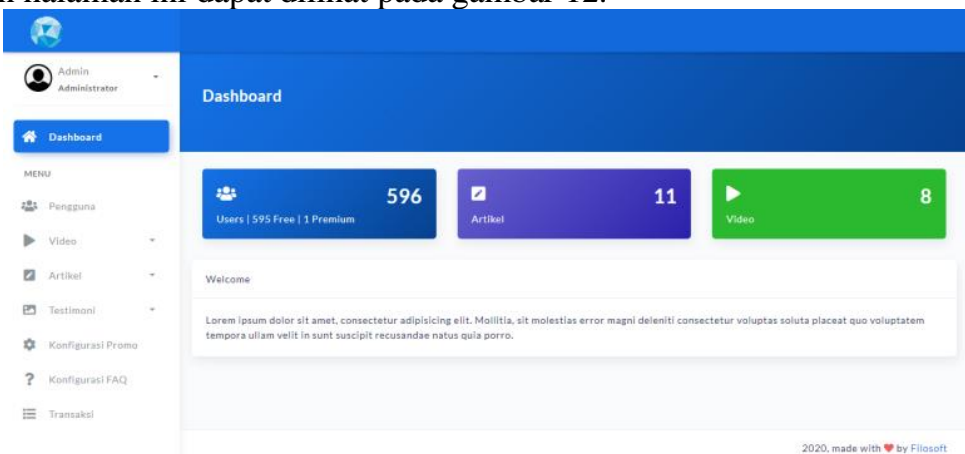

Gambar 12. Halaman Dashboard 
3. Manajemen User

Halaman ini berisi tentang informasi user. Terdapat fitur filter, pengurutan dan juga pencarian data user. Untuk tampilan halaman ini dapat dilihat pada gambar 13.

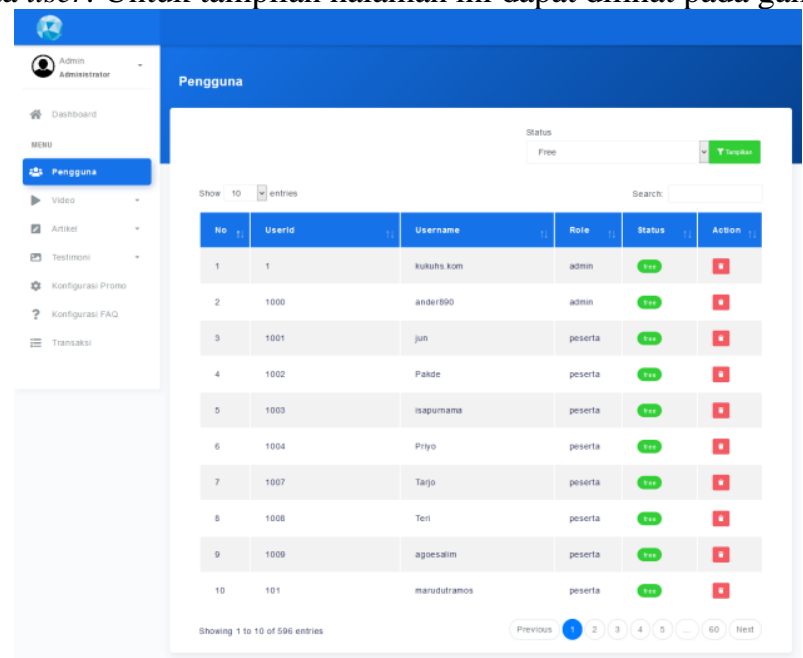

Gambar 13. Halaman Manajemen User

4. Manajemen Screencast

Halaman ini berisi tentang data screencast. Juga fitur tambah, edit, hapus, pengurutan dan juga pencarian data screencast. Untuk tampilan halaman ini dapat dilihat pada gambar 14 .

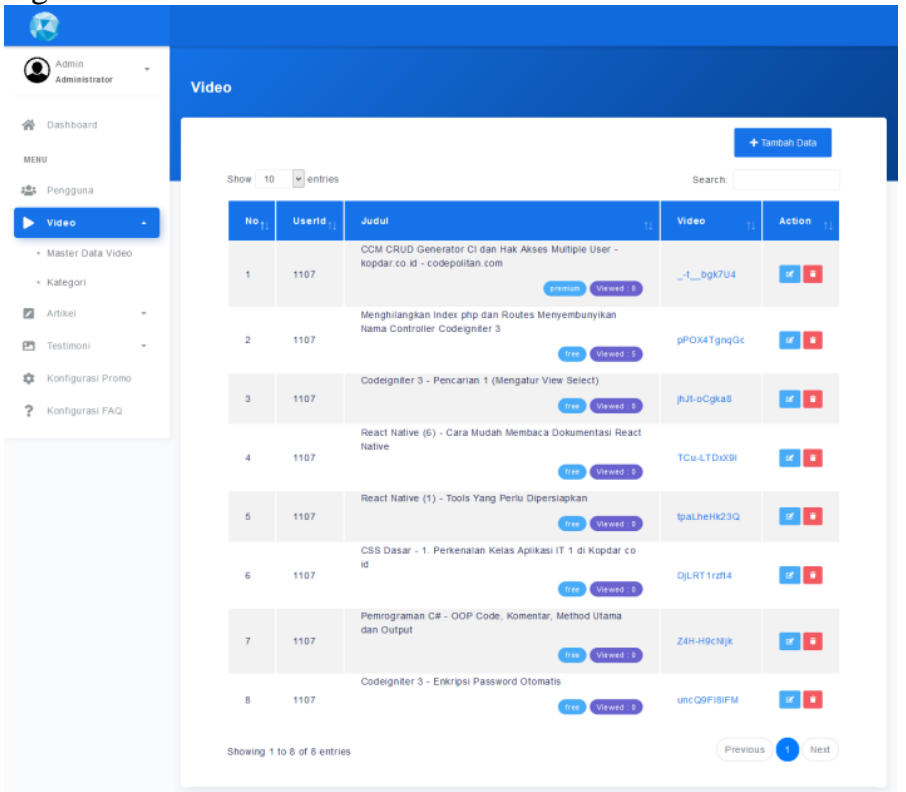

Gambar 14. Halaman Manajemen Screencast 
5. Manajemen Kategori Screencast

Halaman ini berisi tentang data kategori screencast. Juga fitur tambah, edit, hapus, pengurutan dan juga pencarian data kategori screencast. Untuk tampilan halaman ini dapat dilihat pada gambar 15 .

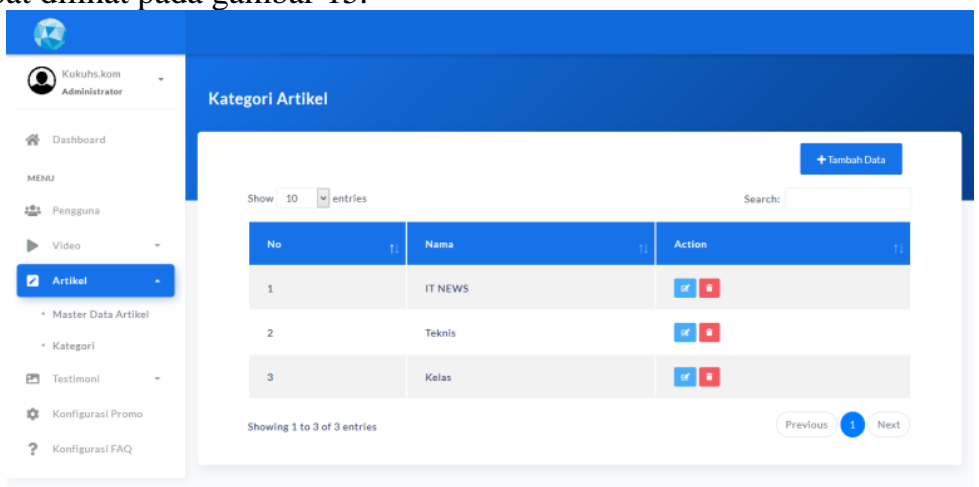

Gambar 15. Halaman Kategori Screencast

6. Manajemen Kategori Artikel

Halaman ini berisi tentang data kategori artikel. Juga fitur tambah, edit, hapus, pengurutan dan juga pencarian data artikel. Untuk tampilan halaman ini dapat dilihat pada gambar 16.

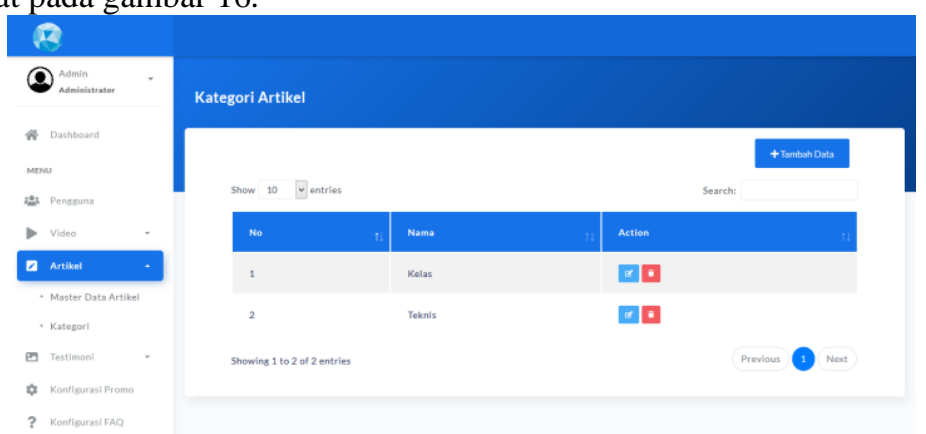

Gambar 16. Halaman Kategori Artikel 
7. Manajemen Testimoni

Halaman ini berisi tentang data testimoni. Juga fitur tambah, pengurutan, hapus dan juga pencarian data artikel. Untuk tampilan halaman ini dapat dilihat pada gambar 17.

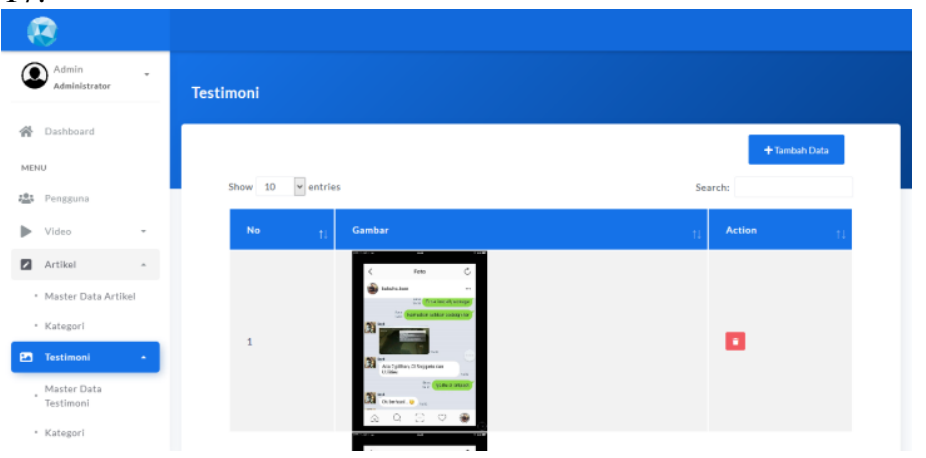

Gambar 17. Halaman Manajemen Testimoni

8. Manajemen Artikel

Halaman ini berisi tentang data artikel. Juga fitur tambah, edit, hapus, pengurutan dan juga pencarian data artikel. Untuk tampilan halaman ini dapat dilihat pada gambar 18.

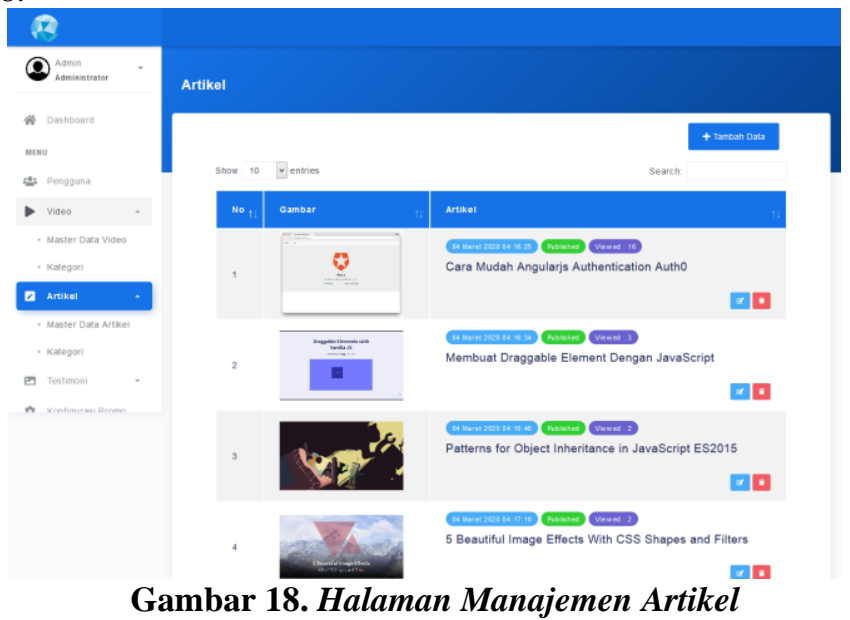


9. Manajemen Kategori Testimoni

Halaman ini berisi tentang data screencast. Juga fitur tambah, filter, pengurutan dan juga pencarian data kategori testimoni. Untuk tampilan halaman ini dapat dilihat pada gambar 19.

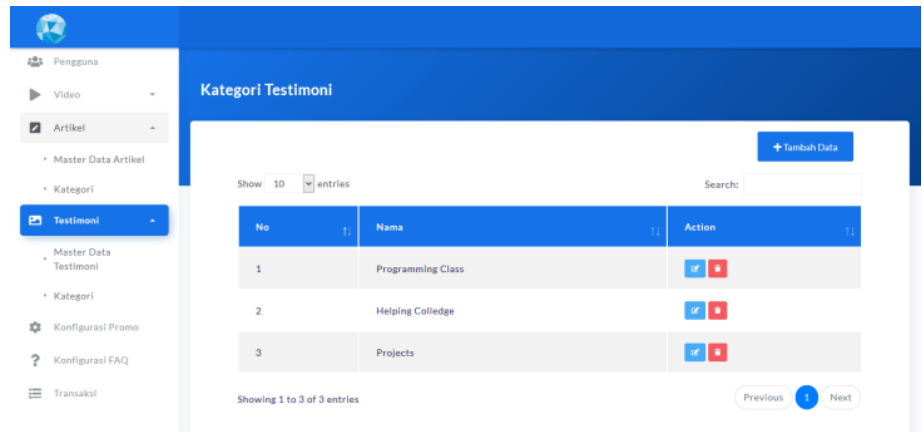

Gambar 19. Halaman Kategori Testimoni

10. Manajemen Promo

Halaman ini bertujuan untuk mengkonfigurasi promo yang sedang berjalan, nomor rekening, dan harga untuk upgrade akun premium. Untuk tampilan halaman ini dapat dilihat pada gambar 20 .

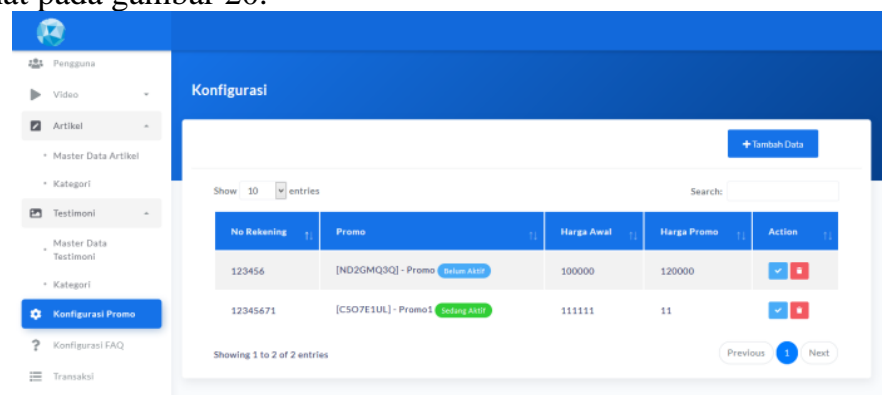

Gambar 20. Halaman Manajemen Promo 
11. Manajemen Pertanyaan

Halaman ini berisi tentang datapertanyaan. Juga fitur tambah, edit, hapus, pengurutan dan juga pencarian data pertanyaan. Untuk tampilan halaman ini dapat dilihat pada gambar 21 .

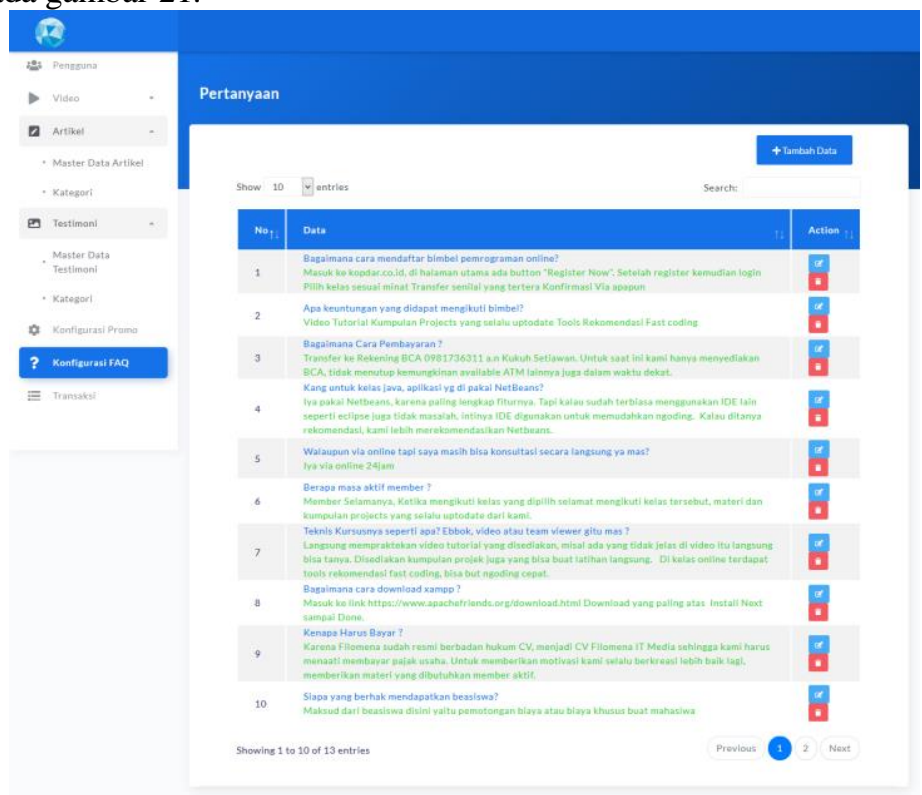

Gambar 21. Halaman Manajemen Faq

12. Manajemen History Payment

Halaman ini bertujuan untuk melihat Riwayat pembayaran dan informasi detail transaksi yang telah dilakukan oleh user. Untuk tampilan halaman ini dapat dilihat pada gambar 22 .

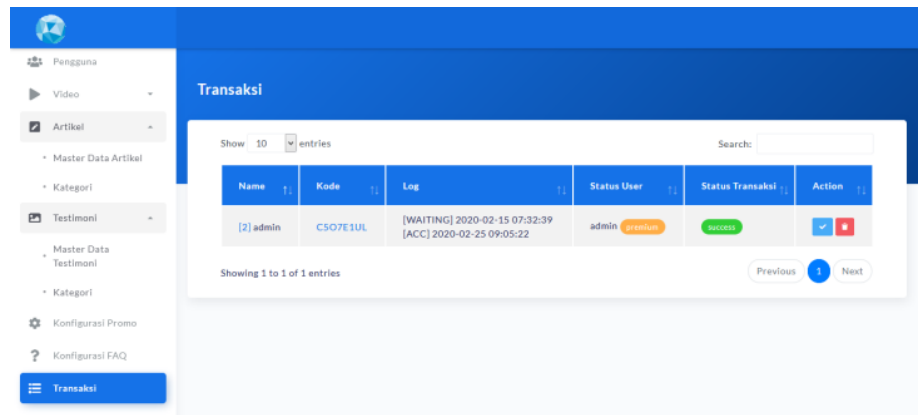

Gambar 22. Halaman History Payment

\section{KESIMPULAN}

Dari hasil penelitian ini dapat disimpulkan bahwa penggunaan codeigniter sangat efektif dan mempersingkat waktu dalam mengembangkan software skala menengah. Penggunaan Social Media Authentication lebih memberikan keamanan dan kemudahan sehingga hanya dengan me-login-kan social media di browser yang sama user tidak perlu memasukkan username dan password saat login. Dengan menggunakan framework versi terbaru maka struktur kode akan tetap bisa berjalan sebagaimana mestinya selama beberapa tahun kedepan. Untuk penyempurnaan tahap selanjutnya dari aplikasi ini sebaiknya 
pada Admin Panel proses menampilkan data relatif lebih lama bila data yang dimuat lebih besar. Jadi diharapkan pada pengembangan selanjutnya bisa menggunakan query secara lebih optimal. Untuk pengembangan selanjutnya, diharapkan bisa menggunakan konfirmasi dari email.

\section{DAFTAR PUSTAKA}

[1] Ilmi, M., Said, D., Hadi, A. 2016. "Perancangan Sistem Informasi Pernikahan Dan Status Pernikahan Kantor Uurusan Agama Kecamatan Canduang Agam Berbasis Web Dengan Framework Codeigniter". Jurnal Vokasional Teknik Elektronika \& Informatika. Vol. 4. No. 1

[2] Dermawan, Putra, S., Kusuma, L. 2020. “Aplikasi Pendaftaran Seminar Menggunakan Metode MVC Berbasis Website Menggunakan Framework Codeigniter 3.1.10”. JURNAL ALGOR. VOL. 1 NO. 2

[3] Pradikta, A., Haryono, D., 2015. “Aplikasi Video Pembelajaran dengan Konsep Youtube”. SATIN - Sains dan Teknologi Informasi. Vol. 1. No. 1

[4] Subari, A., Tadeus, Y., D., Winarno, H., et al. 2017. "Rancang Bangun Sistem Administrasi Kerja Praktek dan Tugas Akhir Berbasi Web dengan menggunakan framework codeigniter". GEMA TEKNOLOGI, Vol. 19. No. 4

[5] Wansyah, A., Susandri. 2017. "Teknologi Pemrograman Framework Model View Controller pada Sistem Infromasi Penasehat Akademis".Jurnal PROCESSOR. Vol. 12. No. 1.

[6] Heriyanto, B., Kurniawan, I., dan Taufik, I. 2017. "Sistem Aplikasi Perpustakaan Berbasis Web Menggunakan Framework Codeigniter pada SMAS Islamic Centre". Jurnal Ilmiah SISFOTENIKA, Vol. 7. No. 2.

[7] Istiono, W., Hijrah, dan Sutarya. 2016. "Pengembangan Sistem Aplikasi Penilaian dengan Pendekatan MVC dan Menggunakan Bahasa PHP dengan Framework Codeigniter dan Database MYSQL pada Pahoa College Indonesia". Jurnal TICOM.

[8] Herlawati, dan Prabowo P. 2011. Menggunakan Uml. Bandung: Informatika.

[9] Hendini, A. 2016. "PEMODELAN UML SISTEM INFORMASI MONITORING PENJUALAN DAN STOK BARANG (STUDI KASUS: DISTRO ZHEZHA PONTIANAK". Jurnal Khatulistiwa Informatika, VOL. IV 